into. In the Bantu language Kivunjo, he tells us, the verb form Näikìmlyïà, meaning "He is eating it for her", is one of about half a million possible forms, which native speakers have no trouble in assembling on the fly from bits and pieces such as these:

$\mathrm{N}$ - A marker indicating that the word is the 'focus' of that point in the conversation.

-ä- A subject agreement marker, identifying the eater as falling into class 1 of the 16 gender classes, 'human singular'. Other genders (kinds, not sexes) embrace nouns that pertain to several humans, thin or extended objects, objects that come in pairs or clusters, the pairs or clusters themselves, instruments, animals, body parts, diminutives (small or cute versions of things), abstract qualities, precise locations and general localities.

-i- Present tense. Other tenses in Bantu can refer to today, earlier today, yesterday, no earlier than yesterday, yesterday or earlier, in the remote past, habitually, ongoing, consecutively, in the future, at an indeterminate time, not yet and sometimes.

-kì- An object agreement marker, in this case indicating that the thing eaten falls into gender class 7

And so on.

One of the mysteries Pinker does not resolve for the inquisitive reader is the precise relationship between the earlyand the late-flowering varieties of Chomskian linguistic theory. His reasons may be diplomatic, or simply expository: a fear of the pedagogic confusion that might result from attempting to superimpose the most recent version of "GB theory" on the "Xbar theory" to which he has so carefully introduced the reader. Perhaps he merely felt it wiser to hide the antics of the professional linguists from the searching gaze of student innocence.

For all other readers, The Language Instinct will illuminate every facet of human language: its biological origin, its uniqueness to humanity, its acquisition by children, its grammatical structure, the production and perception of speech, the pathology of language disorders and the unstoppable evolution of languages and dialects. With its wealth of examples, its flawless typesetting, its wide-ranging bibliography and its irresistible good humour, Pinker's book is certain to increase its readers' respect for the amazing natural phenomenon that the author and his colleagues have made their life's (to a maven, lives'?) study.

Christopher Longuet-Higgins is in the Laboratory of Experimental Psychology, University of Sussex, Falmer, Brighton BN1 9QG, UK.

\title{
Reactions speak louder than words
}

\section{Roald Hoffmann}

La Parole des Choses. By Pierre Laszlo. Hermann: 1993. Pp. 320. FFr160.

THERE has always been a link between language and chemistry. Lavoisier begins his revolutionary Traité Elémentaire de Chimie with a quote from the Abbe de Condillac: "We think only through the medium of words. Languages are true analytical methods." Lavoisier then reflects on his own work: "Thus, while I thought of myself employed only in forming a Nomenclature... my work transformed itself by degrees, without my being able to prevent it, into a treatise upon the Elements of Chemistry". The distinguished European writer Elias Canetti, author of a remarkable study of mass behaviour, Crowds and Power, and a striking novel of the 1930s, Auto da Fé, earned a PhD in chemistry. He credits chemistry with teaching him the importance of linguistic structure. And Benjamin Lee Whorf, the great American linguist who made a case for language shaping culture, trained as a chemical engineer at the Massachusetts Institute of Technology. Whorf was not averse to "an occasional chemical simile". In an essay on languages and logic he writes: "the way the constituents are put together in these sentences of Shawnee and Nootka suggests a chemical compound, whereas their combination in English is more like a mechanical mixture".

Pierre Laszlo's rich and original book explains the link between language and chemistry. Laszlo makes an analogy between molecules and their transformations on one hand and linguistic structures such as morphemes, phonemes, ideograms and pictograms, transformations of mode and description on the other. If the latter sound abstruse to a chemist, imagine what sense a functional group, elementary reactions, $\mathrm{C}_{6} \mathrm{H}_{6}$ or a benzene ring drawn out (of course, without a $\mathrm{C}$ or $\mathrm{H}$ indicated) would make to a linguist other than the late Whorf.

La Parole des Choses (perhaps one way to translate the title is "The Way Things Speak", but that doesn't capture the allusion to the structuralist and literary theory use of parole) is actually two books. The working out of the language-chemistry analogy is one theme that runs through this readable volume. Another theme, interwoven, is simply that of the beauty of chemistry. The logic of the molecular science is masterfully explicated, with few compromises, for an intelligent reader outside chemistry. For instance, the book contains a beautiful discussion of nitrogen inversion, the best short introduction to nuclear magnetic resonance I've read and even a brief account of femtosecond reactions. But consistent with Laszlo's broad cultural theme, these expositions are juxtaposed with, respectively, a quote from Gérard de Nerval (a nineteenth-century French poet and writer), a touching retelling of some of Laszlo's misadventures in taking his first NMR spectrum in 1961, and an excerpt from Blake's Milton.

Insights and information abound. The linguistic analogy builds convincingly, but one does not have to buy into it to appreciate the capsule description of the economics of the perfume industry (and the composition of "Obsession") or the surprising use by Hegel of Berzelius's electrochemical theory or the prolonged alchemical and chemical use of the word menstruum for solvent.

Let me see if I can put my finger more precisely on the value in this book. To deconstruct scientific texts is so easy, too easy. Ditto for the use of literary allusions to pretty up science writing. Laszlo does something more - he sets up an intriguing analogy, of the processes of language and chemistry, and lets the analogy illuminate each field.

Roald Hoffmann is in the Department of Chemistry, Cornell University, Ithaca, New York 14853-1301, USA.

\section{Linguistic geography}

\section{Mark Pagel}

Atlas of the World's Languages. Edited by Christopher Moseley and R. E. Asher. Routledge: 1994. Pp. 372. £395, $\$ 599.95$.

FIFTEEN years ago, one respected encyclopaedia of the world's languages placed the number of known extant human languages at around 4,550. By 1984 a new survey found that at least 5,450 different languages were being spoken on Earth. The number rose to 6,170 by the time of the appearance of the eleventh edition of Ethnologue: Languages of the World (edited by B. F. Grimes, Summer Institute of Linguistics, 1988), and to more than 6,500 by the twelfth edition. The true number is probably even higher. This diversity of languages, all of them spoken by the same species, is testimony to the human - one might say - compulsion to speak. Unlike chimpanzees, which need daily operant prodding to use even a small repertoire of words, it is difficult to stop humans from using language: linguists 
have even observed groups of young children spontaneously create fully fledged languages. Whoever said that our ability to use language is not an adaptation?

The earliest language was probably first spoken sometime within the past 100,000 years. Nobody knows what this language was like, but it may have left traces: a few sounds seem to recur in most languages. The most celebrated is 'tik' which seems to be associated with words for 'one', 'finger' or 'digit' in many languages (toe?). Nevertheless, languages are in a constant state of Heraclitean flux and they evolve at a much higher rate than most biological traits. A rule of thumb is that a language will replace 15-20 per cent of its fundamental vocabulary per millennium with

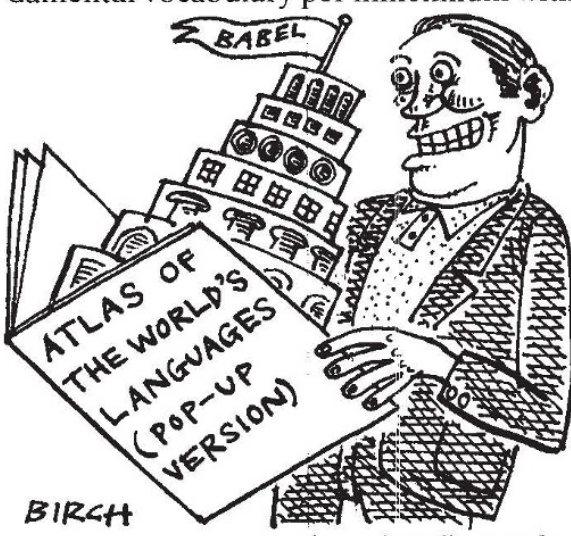

new or non-cognate (unrelated) words. Two 'sister languages' that stem from a common ancestor acquire differences between them at twice the rate, and may become mutually unintelligible in about 500 years. Subtle differences may appear rather sooner. The English do not mind being asked what time they would like to be 'knocked-up' in the morning, but an American will blush. A conversation with the Venerable Bede would be even more challenging.

The fast pace of language evolution probably means that hundreds of thousands of different languages have been heard on Earth since humans started talking. Most of these will have either evolved into something new over time or have been replaced by a different language. But the rate at which languages become extinct may be dramatically increasing. Some linguists believe that as many as 3,000 languages will become extinct over the next century. The causes are obvious. A few languages, some owing to colonialism and trade, others to despotism, yet others to human biological fertility, have become ascendant: threequarters of the world's population speak a language from a list of 20 . Where English is spoken, typically between 80 and 90 per cent of the native languages have been lost. In Russia, some 70 per cent of the indigenous languages are moribund.

Routledge's monolithic new Atlas of the World's Languages provides an unprecedented account of the linguistic composi- tion of the world. Many previous books on the world's languages have adopted the title of encyclopaedia, but this atlas is the first to provide maps showing the geographical reach of each language. Each of the 135 colour maps contains a numbered and colour-coded key. Those for the Americas and Australia record the languages as they probably were at the beginning of European colonial expansion, and as they are now. These 'time-of-contact' maps will allow scholars to investigate the way in which language groups contract, or in some cases adapt, in response to an incoming language and society. Accompanying the maps are accounts of the linguistic history of each area, probable relationships among the languages and estimates of the number of contemporary speakers based on recent surveys. Not surprisingly, a work of this magnitude is the result of the efforts of many people: Moseley and Asher assembled 14 other linguists, along with numerous collaborators, to contribute to the volume during a gestation of several years.

So large a contribution is the atlas that I predict it will stimulate its own cottage industry of geographical linguistic research. The world's Tower of Babel is the island of New Guinea with more than 1,000 different languages spoken in 310,000 square miles. Compare this to China with only 90 languages in an area 12 times the size. One of those 90, Mandarin, is spoken by 711 million people. Africa contributes about 2,000 languages, the Americas another 900, whereas Europe and the Middle East have only about 300 . Maps of Australia show that more than 400 aboriginal languages were spoken at the time of European contact. Now, by my counts from the atlas's tables of numbers of speakers, at least 205 are either extinct or have so few speakers that the number is unknown. A further 150 are spoken by fewer than 30 people, an amount below which linguists consider a language not to be viable. Dividing Australia into northern and southern regions using the atlas's maps makes clear that the loss of linguistic diversity is much more pronounced in the south - the areas of greatest European settlement in Australia. In Alaska, only two language subgroups - Central Yupik Eskimo and Siberian Yupik Eskimo -- are still taught to children. Another 45 or 50 native Alaskan or northern Siberian languages are either extinct or may become so in a generation.

Languages and language evolution do not depend for their own survival on the survival of their biological carriers. Like viruses infecting new bodies, elements of language can quickly jump from mind to mind, changing along the way. This is at least partly why languages evolve so quickly. But this also accounts for why a language can equally quickly displace another, even if there are no changes to the population of speakers. The loss of any human language is the loss of a communication system as fully developed as one's own - all the different human languages are regarded as roughly equally complex. E. Sapir and B. L. Whorf advanced the idea that language structures the mind. One's language is not only the language in which one thinks, it influences the way in which one thinks. Sapir said that "we see and hear and otherwise experience very largely as we do because the language habits of our community predispose certain choices of interpretation". An English-speaking person's mind is different from that of a French speaker, and that of a German speaker, and that of the few remaining speakers of North Frisian, a phenomenon that must contribute a certain ennui to European Union negotiations. Sapir and Whorf were criticized for their idea earlier this century, but it has now caught the imagination of linguists and philosophers of mind.

So the loss of a language is the loss of a 'way of mind' for its speakers. The last speaker of a language (and there are many) must confront a stark and wretched isolation. The loss of a language is also the loss of a dimension of consciousness: there are 80 consonants in Ubykh and the Pintupi have at least ten words for a hole in the ground. Some linguists believe that as few as 500 languages may survive the twenty-first century. In not too many years it may be apt to describe the world as narrow-minded.

Mark Pagel will shortly join the Department of Zoology, University of Oxford, Oxford OX1 3PS, UK.

\section{Diversity of life}

\section{Michael Taylor}

The Common But Less Frequent Loon and Other Essays. By Keith Stewart Thomson. Yale University Press: 1994. Pp. 186. $\$ 25, £ 17.95$.

To some Scots (as once to Shakespeare) a loon is the young farmworker whose premachine lifestyle was recorded in David Cameron's The Ballad and the Plough. Not inappropriately, either: in this collection of essays, drawn in part from Thomson's "Marginalia" column in American Scientist, Thomson turns his hand from electric fish to mass extinctions to nineteenth-century zoology just as the loon (or loun) went from hay-making to swede-singling, ploughing to harvesting.

Actually, Thomson's loon inhabits not Scottish 'fermtouns' but North American lakes. Thomson, a native Briton, is now president of the Philadelphia Academy of Natural Sciences, so of course the 'common loon' is Gavia immer, a large and 